Session 12-10

\title{
Approximation of Internal Energy and Enthalpy of Fluids in the Compressed Liquid Region
}

\author{
Isa Tan \\ Mechanical Engineering Department \\ The University of Texas at San Antonio \\ Dr. Amir Karimi, Graduate Advisor \\ Mechanical Engineering Department \\ The University of Texas at San Antonio
}

\begin{abstract}
The approximation of thermodynamic properties of compressed liquids at a given temperatures and pressures is currently based on the saturated liquid properties at the given temperatures only. For example, it is a common practice to approximate specific volume, $v(T, p)$, by saturated liquid specific volume, $\mathrm{v}_{\mathrm{f}}(\mathrm{T})$, the specific internal energy, $\mathrm{u}(\mathrm{T}, \mathrm{p})$, by saturated liquid specific internal energy, $u_{f}(T)$, the specific entropy, $s(T, p)$, by saturated liquid specific entropy, $s_{f}(T)$, and the specific enthalpy, $h(T, p)$, by $h_{f}(T)+v_{f}(T)\left[p-p_{s a t}(T)\right]$. Errors resulting from these approximations will be analyzed in this paper. This paper will show that these approximations are not very accurate at all ranges of temperatures and pressures. The paper will establish limits on the range of pressures and temperatures that these approximations could be used with reasonable accuracies. The paper will also show that the approximations based on constant entropy yield much higher accurate results than those based on a constant temperature. For example, the approximation of $u(s, p)$ by $u_{f}(s)$ is much more accurate that the approximation of $\mathrm{u}(\mathrm{T}, \mathrm{p})$ by $\mathrm{u}_{\mathrm{f}}(\mathrm{T})$. The paper will go through analysis showing how the saturated liquid properties could be used to achieve a more accurate approximation of thermodynamic properties in the compressed liquid region.
\end{abstract}

\section{Introduction}

\section{Background}

It is a common practice to approximate thermodynamic properties of fluids in the compressed liquid region, using the saturated liquid data of specific volume, internal energy and entropy at a given temperature and pressure are approximated by

$$
\begin{aligned}
& \mathrm{v}(\mathrm{T}, \mathrm{p}) \approx \mathrm{v}_{\mathrm{f}}(\mathrm{T}) \\
& \mathrm{u}(\mathrm{T}, \mathrm{p}) \approx \mathrm{u}_{\mathrm{f}}(\mathrm{T}) \\
& \mathrm{s}(\mathrm{T}, \mathrm{p}) \approx \mathrm{S}_{\mathrm{f}}(\mathrm{T})
\end{aligned}
$$

in most Thermodynamic textbooks ${ }^{1,2}$. Also, specific enthalpy is defined as

$$
\begin{aligned}
& \mathrm{h}=\mathrm{u}+\mathrm{pv} \\
& \text { Proceedings of the } 2008 \text { ASEE Gulf-Southwest Annual Conference } \\
& \text { The University of New Mexico - Albuquerque } \\
& \text { Copyright (C) 2008, American Society for Engineering Education }
\end{aligned}
$$


and in a differential format

$$
\mathrm{dh}=\mathrm{du}+\mathrm{pdv}+\mathrm{vdp}
$$

Integrating along constant temperature, the following relationship results

$$
\left.\left.\left.\left.\int_{h_{f}}^{h(p)} d h\right)_{T}=\int_{u_{f}}^{u(p)} d u\right)_{T}+\int_{\mathrm{v}_{\mathrm{f}}}^{\mathrm{v}(\mathrm{p})} p d \mathrm{v}\right)_{T}+\int_{P \text { sat }}^{P} d p\right)_{T}
$$

To approximate the enthalpy in the liquid region, most Thermodynamic textbooks ${ }^{1,2}$ use the argument that $\mathrm{u}$ and $\mathrm{v}$ are independent of pressure in the compressed liquid region. Therefore,

$$
\left.\left.\int_{u_{f}}^{u(p)} d u\right)_{T}=\int_{v_{f}}^{v(p)} p d v\right)_{T}=0
$$

Thus equation (6) reduces to

$$
\left.\left.\int_{h_{f}}^{h(p)} d h\right)_{T}=\mathrm{v}_{\mathrm{f}} \int_{\text {Psat }}^{P} d p\right)_{T}
$$

Integrating equation (8) the following approximation is obtained

$$
\mathrm{h}(\mathrm{p}, \mathrm{T})-\mathrm{h}_{\mathrm{f}}(\mathrm{T})=\mathrm{v}_{\mathrm{f}}(\mathrm{T})\left[\mathrm{p}-\mathrm{p}_{\mathrm{sat}}(\mathrm{T})\right]
$$

Then equation (9) becomes as described in the thermodynamic textbooks as,

$$
\mathrm{h}(\mathrm{p}, \mathrm{T})=\mathrm{h}_{\mathrm{f}}(\mathrm{T})+\mathrm{v}_{\mathrm{f}}(\mathrm{T})\left[\left(\mathrm{p}-\mathrm{p}_{\mathrm{sat}}(\mathrm{T})\right]\right.
$$

Kostic $^{3,4}$ observed that the recommended pressure correction (second term in equation (10) for enthalpy of liquid water is accurate at low temperatures but erroneous at high temperatures and pressures. He also noticed that pressure correction is not necessary for intermediate pressure and temperatures. In fact he has argued that adding the correction term

$$
\mathrm{v} \Delta \mathrm{p}=\mathrm{v}_{\mathrm{f}}(\mathrm{T})\left[\mathrm{p}-\mathrm{p}_{\mathrm{sat}}(\mathrm{T})\right]
$$

will contribute larger errors. 
Table 1. Specific Internal Energy and Enthalpy of Liquid Water at $260{ }^{\circ} \mathrm{C}^{3}$

\begin{tabular}{|l|r|r|r|r|r|r|r|r|r|}
\hline State & \multicolumn{1}{c|}{$\mathrm{p}$} & $\mathrm{h}(\mathrm{T}, \mathrm{p})$ & $\Delta \mathrm{h}_{\mathrm{f}}$ & \multicolumn{1}{c|}{$\mathrm{h}_{\mathrm{app}}$} & $\Delta \mathrm{h}_{\mathrm{app}}$ & $\mathrm{v}(\mathrm{T}, \mathrm{p})$ & $\mathrm{u}(\mathrm{T}, \mathrm{p})$ & \multicolumn{1}{c|}{$\Delta \mathrm{u}$} & $\mathrm{v}_{\mathrm{f}}\left(\mathrm{p}-\mathrm{p}_{\text {sat }}\right)$ \\
\hline & {$[\mathrm{Mpa}]$} & {$[\mathrm{kJ} / \mathrm{kg}]$} & $\mathrm{kJ} / \mathrm{kg}$ & {$[\mathrm{kJ} / \mathrm{kg}]$} & {$[\mathrm{kJ} / \mathrm{kg}]$} & {$\left[\mathrm{m}^{3} / \mathrm{kg}\right]$} & \multicolumn{3}{|c|}{$[\mathrm{kJ} / \mathrm{kg}]$} \\
\hline Sat & 4.688 & 1134 & 0.0 & 1134.4 & 0.0 & 0.0013 & 1128 & 0.0 & 0.0 \\
\hline Comp & 5 & 1134 & -0.1 & 1134.7 & 0.3 & 0.0013 & 1128 & -0.5 & 0.4 \\
\hline Comp & 10 & 1134 & -0.7 & 1140.4 & 6.0 & 0.0013 & 1121 & -7.3 & 6.7 \\
\hline Comp & 15 & 1133 & -1.0 & 1146.4 & 12.0 & 0.0013 & 1115 & -13.8 & 13.0 \\
\hline Comp & 20 & 1134 & -0.9 & 1152.8 & 18.4 & 0.0013 & 1109 & -19.8 & 19.3 \\
\hline Comp & 30 & 1134 & -0.1 & 1166.0 & 31.6 & 0.0012 & 1097 & -31.0 & 31.7 \\
\hline Comp & 50 & 1138 & 3.8 & 1194.4 & 60.0 & 0.0012 & 1078 & -50.3 & 56.2 \\
\hline
\end{tabular}

Table 1 is a reproduction of the enthalpy and internal energy data points presented by Kostic in ${ }^{3}$, ${ }^{4}$ for water at $260{ }^{\circ} \mathrm{C}$. In this table $\mathrm{h}_{\text {app }}$ is the approximation of $\mathrm{h}(\mathrm{T}, \mathrm{P})$ from equation $(10)$

$$
\begin{aligned}
& \Delta \mathrm{u}=\mathrm{u}(\mathrm{T}, \mathrm{p})-\mathrm{u}_{\mathrm{f}}(\mathrm{T}) \\
& \mathrm{v} \Delta \mathrm{p}=\mathrm{v}_{\mathrm{f}}(\mathrm{T})\left[\mathrm{p}-\mathrm{p}_{\mathrm{sat}}(\mathrm{T})\right] \\
& \Delta \mathrm{h}_{\mathrm{f}}=\mathrm{h}(\mathrm{T}, \mathrm{p})-\mathrm{h}_{\mathrm{f}}(\mathrm{T}) \\
& \Delta \mathrm{h}_{\mathrm{app}}=\mathrm{h}_{\mathrm{app}}-\mathrm{h}_{\mathrm{f}}
\end{aligned}
$$

Table 1 shows that along the $260{ }^{\circ} \mathrm{C}$ isotherm, $\mathrm{h}(\mathrm{T}, \mathrm{p})=\mathrm{h}_{\mathrm{f}}(\mathrm{T})$ is a better approximation than that obtained from equation (10).

Table 1 also shows that internal energy, $\mathrm{u}$, for water at $260{ }^{\circ} \mathrm{C}$ varies with pressure. For example $\mathrm{u}_{\mathrm{f}}$ at $260{ }^{\circ} \mathrm{C}$ is equal to $1128.4 \mathrm{~kJ} / \mathrm{kg}$. However for the same temperature but at $50 \mathrm{MPa}$ the specific internal energy is $1078.1 \mathrm{~kJ} / \mathrm{kg}$. Therefore the internal energy is not only a function of temperature, but also a function pressure in the compressed liquid region.

The focus of this work is to determine if the behavior described by Kostic is unique to water or if this behavior extends to other substances. We would like to determine whether $v(T, p), u(T, p)$, and $s(T, p)$ are independent of pressure in the compressed liquid region. In addition we are interested to determine the range of pressures and temperatures where thermodynamic properties of substances in the compressed liquid region could be approximated by equations (1), (2), (3), and (10). In this work, we will also derive equations for the approximation of $u(T, p)$ and $h(T$, p), using the saturation properties.

\section{Fundamental Equations}

Fundamental relation for specific internal energy, in differential form, is usually expressed as a function of entropy, s, and specific volume, $\mathrm{v}$

$$
\mathrm{du}=\mathrm{Tds}-\mathrm{pdv}
$$

the specific enthalpy is defined as 


$$
\mathrm{h}=\mathrm{u}+\mathrm{pv}
$$

in differential form

$$
\mathrm{dh}=\mathrm{du}+\mathrm{pdv}+\mathrm{vdp}
$$

substituting equation (16) into equation (17) results in

$$
\mathrm{dh}=\mathrm{Tds}+\mathrm{vdp}
$$

Helmholtz free energy is defined as

$$
\mathrm{f}=\mathrm{u}-\mathrm{Ts}
$$

in differential form

$$
\mathrm{df}=\mathrm{du}-\mathrm{sdT}-\mathrm{Tds}
$$

substituting equation (16) into equation (20), the Helmholtz free energy can be expressed as a function of temperature, $\mathrm{T}$, and volume, $\mathrm{v}$

$$
\mathrm{df}=-\mathrm{sdT}-\mathrm{pdv}
$$

Gibbs function is expressed as

$$
\mathrm{g}=\mathrm{h}-\mathrm{Ts}
$$

in differential form,

$$
\mathrm{dg}=\mathrm{dh}-\mathrm{Tds}-\mathrm{sdT}
$$

Substituting equation (17) into equation (23) Gibbs free energy can be expressed as a function of temperature, $\mathrm{T}$, and pressure, $\mathrm{p}$

$$
\mathrm{dg}=-\mathrm{sdT}+\mathrm{vdp}
$$

Today, it is a common practice to use Helmholtz free energy to formulate thermodynamic properties. For example Keenan, et.al. ${ }^{5}$, Karimi, Lienhard ${ }^{6}$, and Wagner ${ }^{7}$ have used Helmholtz free energy to formulate the properties of water. Since Hemlholtz free energy is usually expressed as a function of $\mathrm{T}$, and $\mathrm{v}$, in differential format Helmholtz free energy can be expressed as

$$
\left.\left.\mathrm{df}=\frac{\partial \mathrm{f}}{\partial T}\right)_{v} d T+\frac{\partial \mathrm{f}}{\mathrm{dv}}\right)_{T} d \mathrm{v}
$$


Comparing equation (21) with equation (25) results in the following relations

$$
\begin{aligned}
& \left.\mathrm{s}=-\frac{\partial \mathrm{f}}{\partial T}\right)_{v} \\
& \left.\mathrm{p}=-\frac{\partial \mathrm{f}}{\partial \mathrm{v}}\right)_{T}
\end{aligned}
$$

therefore, properties such as internal energy, enthalpy, and Gibbs free energy can be calculated directly from Helmholtz free energy, using equations (4), (19), (22), (26), and (27).

\section{Literature Review}

Kostic investigated the approximation of enthalpy in the compressed liquid region for water 3,4 . He suggested that the approximation formulas included in current thermodynamic textbooks ${ }^{1,2}$ (equations 1, 2, 3, and 10) are not accurate for high temperatures and pressures. He used the National Institute of Standards and Technology (NIST) [9] thermophysical properties software to generate the property values for $\mathrm{v}(\mathrm{T}, \mathrm{p}), \mathrm{u}(\mathrm{T}, \mathrm{p})$ and $\mathrm{h}(\mathrm{T}, \mathrm{p})$ and compared them with the values resulting from the approximation equations. NIST website ${ }^{8}$ provides scientific and technical databases covering a wide range of substances and properties. The digital database used in the calculations has thermophysical property for 74 different fluids. Thermodynamic properties generated by NIST software are based on the Wagner's ${ }^{7}$ IAPWS (International Association for the Properties Water and Steam) formulation for water, Setzman and Wagner's ${ }^{9}$ equation of state for methane, Miyatomo and Watanabe's ${ }^{10}$ thermodynamic properties model for propane, and Tillner, et.al's ${ }^{11}$ equation of state and auxiliary model for ammonia.

Since the calculation of some thermodynamic properties involves finding roots of complex functional relationships, we wanted to check whether the results are dependable. For a few isotherms we used the NIST software to generate data for enthalpy in the compressed liquid region.

Figure 1 shows the variation of specific enthalpy with pressure at given temperatures. These figures show that enthalpy exhibits linear behavior in the compressed liquid region. Figure 1 shows these variations for low temperatures $\left(4{ }^{\circ} \mathrm{C}, 20^{\circ} \mathrm{C}\right.$ and $\left.50^{\circ} \mathrm{C}\right)$. For low and high temperatures, enthalpy increases with pressures.

\section{Analysis}

\section{Approximation of Properties in the Compressed Liquid Region}

Previously it was shown that the equation for the enthalpy,

$$
h(T, p)=h_{f}(T)+v_{f}\left[p-p_{s a t}(T)\right]
$$

is not always accurate for the approximation of enthalpy in the compressed liquid region.

It was shown that along an isotherm the change of enthalpy should be evaluated from the following relationship 


$$
\left.\left.\left.\left.\int_{h_{f}}^{h(p)} d h\right)_{T}=\int_{u_{f}}^{u(p)} d u\right)_{T}+\int_{\mathrm{v}_{\mathrm{f}}}^{\mathrm{v}(\mathrm{p})} p d \mathrm{v}\right)_{T}+\int_{P s a t}^{P} d p\right)_{T}
$$

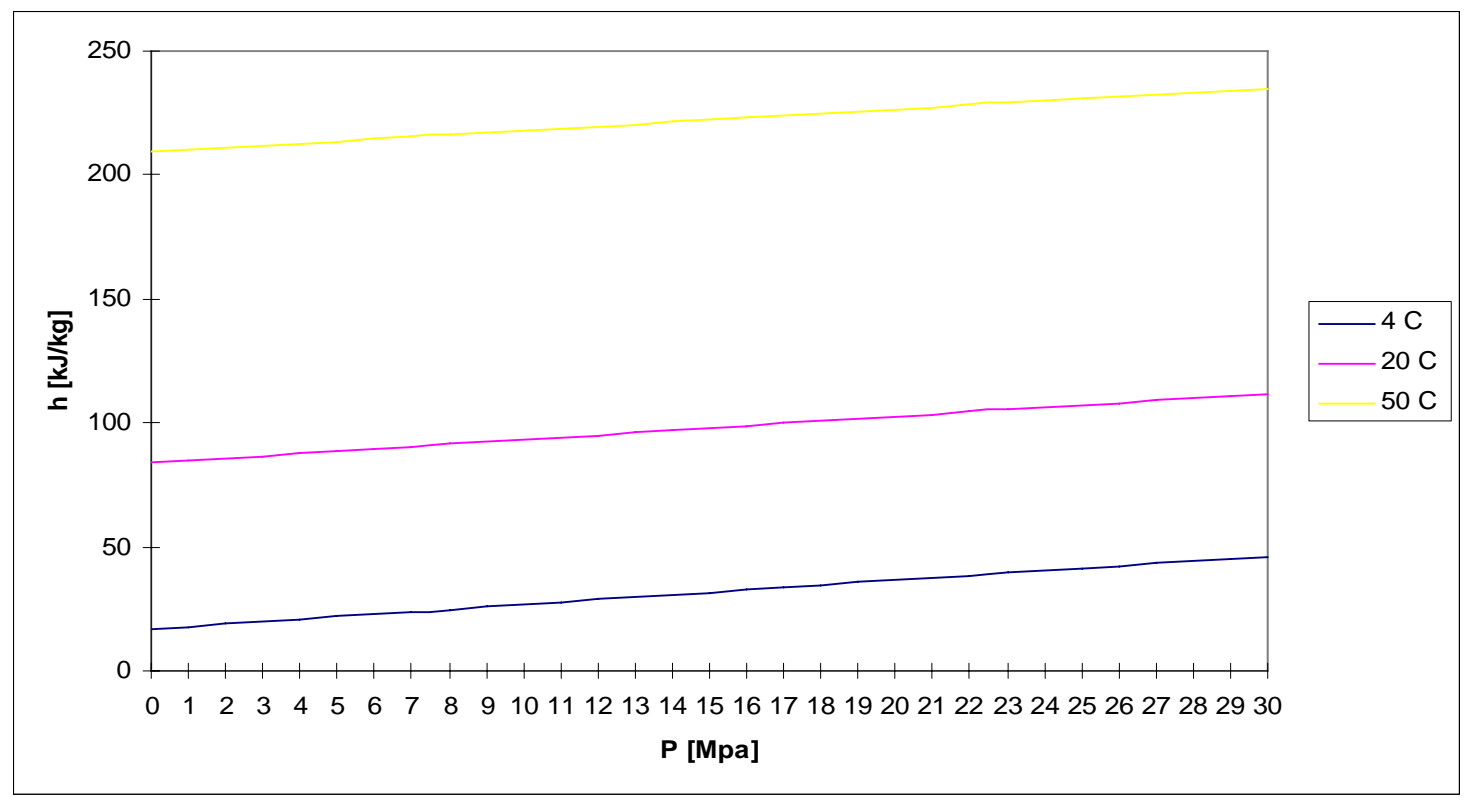

Figure 1. Variation of specific enthalpy with pressure for water at low temperatures

From Kostic's observations ${ }^{3,4}$ it was shown that the assumption that $\left.\int_{P s a t}^{P} d u\right)_{T}=0$ is not always valid in the compressed liquid region. Therefore,

$$
\left.\mathrm{h}(\mathrm{T}, \mathrm{p})=\mathrm{h}_{\mathrm{f}}(\mathrm{T})+\int_{u_{f}}^{u(p)} d u\right)_{T}+\mathrm{v}_{\mathrm{f}}(\mathrm{T})\left[\mathrm{p}-\mathrm{p}_{\mathrm{sat}}(\mathrm{T})\right]
$$

Instead we can show that in the compressed liquid region

$$
\begin{aligned}
& \mathrm{u}(\mathrm{s}, \mathrm{p}) \approx \mathrm{u}_{\mathrm{f}}(\mathrm{s}) \\
& \mathrm{v}(\mathrm{s}, \mathrm{p}) \approx \mathrm{v}_{\mathrm{f}}(\mathrm{s})
\end{aligned}
$$

and,

$$
\mathrm{h}(\mathrm{s}, \mathrm{p})=\mathrm{h}_{\mathrm{f}}(\mathrm{s})+\mathrm{v}_{\mathrm{f}}(\mathrm{s})\left[\mathrm{p}-\mathrm{p}_{\mathrm{sat}}(\mathrm{s})\right]
$$

Using the fundamental relation,

$$
\mathrm{Tds}=\mathrm{dh}-\mathrm{vdp}
$$


Along an isentrop ( isentropic line )

$$
\left.d h)_{s}=\mathrm{vdP}\right)_{s}
$$

Integrating the equation (33) form $\mathrm{P}_{\text {sat }}$ to $\mathrm{P}$;

$$
\left.\left.\int_{h_{f}}^{h(p)} d h\right)_{s}=\int_{P s a t}^{P} v d P\right)_{s}
$$

When we integrate the enthalpy along the isentrop, equation (34) becomes,

$$
\mathrm{h}(\mathrm{s}, \mathrm{p})-\mathrm{h}_{\mathrm{f}}(\mathrm{s})=\int_{P s a t}^{P} \mathrm{v}(s, p) d p
$$

To solve the right side of the equation (35) we have to know a relationship between $\mathrm{v}$ and $\mathrm{p}$. To find this relationship we generated specific volume data as a function of pressure. Table 2 shows that the variations of specific volume and internal energy with pressure are very small along an isentrop. However, Table 3 shows much larger variations of internal energy along an isotherm.

Table 2. Variation of specific volume and internal energy of water with pressure along an isentrop where $\mathrm{s}=\mathrm{s}_{\mathrm{f}}\left(200^{\circ} \mathrm{C}\right)=2.3304[\mathrm{~J} / \mathrm{kgK}]$

\begin{tabular}{|c|c|c|c|c|c|c|}
\hline & $\mathrm{P}$ & $\mathrm{T}(\mathrm{s}, \mathrm{p})$ & $\mathrm{v}(\mathrm{s}, \mathrm{p})$ & $\%$ change in $\mathrm{v}$ & $\mathrm{u}(\mathrm{s}, \mathrm{p})$ & $\%$ change in $\mathrm{u}$ \\
\hline & {$[\mathrm{Mpa}]$} & ${ }^{\mathrm{o}} \mathrm{C}$ & {$[\mathrm{m} 3 / \mathrm{kg}]$} & & {$[\mathrm{kJ} / \mathrm{kg}]$} & \\
\hline sat & 1.5549 & 200.00 & 0.0011565 & 0.00 & 850.47 & 0.00 \\
\hline comp & 10 & 201.39 & 0.0011503 & -0.54 & 850.49 & 0.00 \\
\hline comp & 20 & 203.00 & 0.0011433 & -1.15 & 850.62 & 0.02 \\
\hline comp & 30 & 204.55 & 0.0011367 & -1.74 & 850.77 & 0.04 \\
\hline
\end{tabular}

Table 3. Variation of specific volume and internal energy of water with pressure along an isotherm $\mathrm{T}=200\left[{ }^{\circ} \mathrm{C}\right]$

\begin{tabular}{|c|c|c|c|c|c|}
\cline { 2 - 6 } & $\mathrm{P}$ & $\mathrm{v}(\mathrm{T}, \mathrm{p})$ & $\%$ change in $\mathrm{v}$ & $\mathrm{u}(\mathrm{T}, \mathrm{p})$ & $\%$ change in $\mathrm{u}$ \\
\hline & {$[\mathrm{Mpa}]$} & {$[\mathrm{m} 3 / \mathrm{kg}]$} & & {$[\mathrm{kJ} / \mathrm{kg}]$} & \\
\hline sat & 1.5549 & 0.0011565 & 0.00 & 850.47 & 0.00 \\
\hline comp & 10 & 0.0011482 & -0.72 & 844.31 & -0.73 \\
\hline comp & 20 & 0.0011390 & -1.54 & 837.49 & -1.55 \\
\hline comp & 30 & 0.0011304 & -2.31 & 831.10 & -2.33 \\
\hline
\end{tabular}

In Table 2 the percentage change for specific volume ( $\%$ change in $v$ ) is the error between the specific volume at given entropy and pressure $\mathrm{v}\left(\mathrm{s}_{\mathrm{f}}, \mathrm{p}\right)$, and specific volume at saturation point, $\mathrm{v}_{\mathrm{f}}\left(\mathrm{S}_{\mathrm{f}}\right)$ calculated as: 


$$
\% \text { change in } \mathrm{v}=\frac{\mathrm{v}\left(s_{\mathrm{f}}, p\right)-\mathrm{v}_{\mathrm{f}}\left(s_{\mathrm{f}}\right)}{\mathrm{v}\left(s_{\mathrm{f}}, p\right)} \times 100
$$

Similarly percentage change for internal energy (\%change of $u$ ) is the change between specific internal energy at given entropy and pressure, $u\left(\mathrm{~s}_{\mathrm{f}}, \mathrm{p}\right)$, and specific internal energy at saturation point, $\mathrm{u}_{\mathrm{f}}\left(\mathrm{s}_{\mathrm{f}}\right)$

$$
\% \text { change in } \mathrm{u}=\frac{u\left(s_{\mathrm{f}}, p\right)-u_{\mathrm{f}}\left(s_{\mathrm{f}}\right)}{u\left(s_{\mathrm{f}}, p\right)} \times 100
$$

In these equations $s_{f}=s\left(T_{s a t}\right), v_{f}\left(s_{f}\right)$ is the saturated specific volume at a given entropy, and $u_{f}\left(s_{f}\right)$ is the saturated specific internal energy at a given entropy.

The percentage change, in Table 2.2 are evaluated from the following relations,

$$
\begin{aligned}
& \% \text { change in } \mathrm{v}=\frac{\mathrm{v}(T, p)-\mathrm{v}_{\mathrm{f}}(T)}{\mathrm{v}(T, p)} \times 100 \\
& \% \text { change in } \mathrm{u}=\frac{u(T, p)-u_{\mathrm{f}}(T)}{u(T, p)} \times 100
\end{aligned}
$$

where, $v_{f}(T)$ is saturated specific volume at a given temperature and $u_{f}(T)$ is saturated specific internal energy at a given temperature.

Table 2 shows percentage change in specific volume, (\% change v), and percentage change in specific internal energy, (\% change u), for water at $200{ }^{\circ} \mathrm{C}$. For example specific volume at saturation pressure is equal to $0.0011565 \mathrm{~m}^{3} / \mathrm{kg}$ and specific volume at $30 \mathrm{MPa}$ is equal to 0.0011367 . The change between these two values is $-1.74 \%$. This table also shows that the specific internal energy at saturation pressure is equal to $850.57 \mathrm{~kJ} / \mathrm{kg}$ and specific internal energy at $30 \mathrm{MPa}$ and same temperature is equal to $850.77 \mathrm{~kJ} / \mathrm{kg}$. The change between these two values is $0.035 \%$.

Table 3 shows percentage change in approximating specific volume and internal energy along the $200{ }^{\circ} \mathrm{C}$ isotherm. For example, specific volume of the saturated liquid is $0.0011565 \mathrm{~m}^{3} / \mathrm{kg}$ and specific volume at $30 \mathrm{MPa}$ is equal to $0.0011304 \mathrm{~m}^{3} / \mathrm{kg}$. The change between these to values is $-2.31 \%$. The specific internal energy of saturated liquid is $850.47 \mathrm{~kJ} / \mathrm{kg}$ and at $30 \mathrm{Mpa}$ it is equal to $831.1 \mathrm{~kJ} / \mathrm{kg}$. The change in internal energy is calculated as $-2.3 \%$.

The variations of specific volume are low along an isotherm. It is even lower along an isentrop. Thus, we can assume that specific volume is constant and equal to saturation value along an isentrop. Table 2 also shows that the variation of internal energy with pressure along an isentrop is very small. Then, internal energy and specific volume at a given pressure, could be approximated, 


$$
\mathrm{v}\left(\mathrm{s}_{\mathrm{f}}, \mathrm{p}\right)=\mathrm{v}_{\mathrm{f}}\left(\mathrm{s}_{\mathrm{f}}\right)
$$

and

$$
\mathrm{u}\left(\mathrm{s}_{\mathrm{f}}, \mathrm{p}\right)=\mathrm{u}_{\mathrm{f}}\left(\mathrm{s}_{\mathrm{f}}\right)
$$

The approximation by equation (41) helps us to solve the right side of the equation (31). Assuming constant specific volume, equation (31) reduces to

or,

$$
\mathrm{h}\left(\mathrm{p}, \mathrm{s}_{\mathrm{f}}\right)-\mathrm{h}_{\mathrm{f}}\left(\mathrm{s}_{\mathrm{f}}\right)=\mathrm{v}\left(\mathrm{s}_{\mathrm{f}}\right)\left[\mathrm{p}-\mathrm{p}_{\mathrm{sat}}\right]
$$

$$
\mathrm{h}\left(\mathrm{p}, \mathrm{s}_{\mathrm{f}}\right)=\mathrm{h}_{\mathrm{f}}\left(\mathrm{s}_{\mathrm{f}}\right)+\mathrm{v}\left(\mathrm{s}_{\mathrm{f}}\right)\left[\mathrm{p}-\mathrm{p}_{\mathrm{sat}}\right]
$$

Therefore, equation (42) will give more accurate results then equation (10) for the approximation of the specific enthalpy in the compressed liquid region.

Typically temperature and pressure are given for the calculation of properties in the compressed liquid region. In order to use equations (29), (30), (31), entropy, s(T, p), must first be evaluated from the given temperature and pressures. This will be future discussed in next section.

\section{Approximation Formulation for The Internal Energy}

It was shown that in the compressed liquid region the assumption that internal energy, $\mathrm{u}$, along an isotherm is independent of pressure was not always true. Therefore it will be useful to develop an approximation equation based on saturated liquid properties.

The variation of specific internal energy with pressure along an isentrop was shown in Table 2 . We notice that the temperature increases with pressure along an isentrop. A linear relationship can be developed for temperature as a function of pressure along the isentropic line. In Table 2 it was shown that along an isentrop, the saturation temperature increases from $200{ }^{\circ} \mathrm{C}$ at the saturation pressure to $201.4{ }^{\circ} \mathrm{C}$ at $10 \mathrm{MPa}$ and $204.6{ }^{\circ} \mathrm{C}$ at $30 \mathrm{MPa}$. Figure 2 shows the trend of temperature versus pressure along constant entropy. The trend between temperature and pressure is shown in the Figure 2 to generate the relationship

$$
\mathrm{T}(\mathrm{s}, \mathrm{p})=0.16 \mathrm{p}+199.7
$$

The data in Table 4 helps us to describe a more accurate method to approximate the internal energy at given temperature $\left(200{ }^{\circ} \mathrm{C}\right)$ and pressures. Along an isentrop, temperature increases with the increasing pressure as was shown in Table 2. First column in Table 4 shows the actual value of internal energy at given temperature and pressure. Second column represents the internal energy of the saturated liquid at a given temperature, which is the existing approximation, $\mathrm{u}(\mathrm{T}, \mathrm{p}) \approx \mathrm{u}_{\mathrm{f}}(\mathrm{T})$, for the internal energy. Third column is the temperature at a given entropy and pressure. The last column represents the proposed approximation of internal energy, $\mathrm{u}_{\text {app. }}$. 


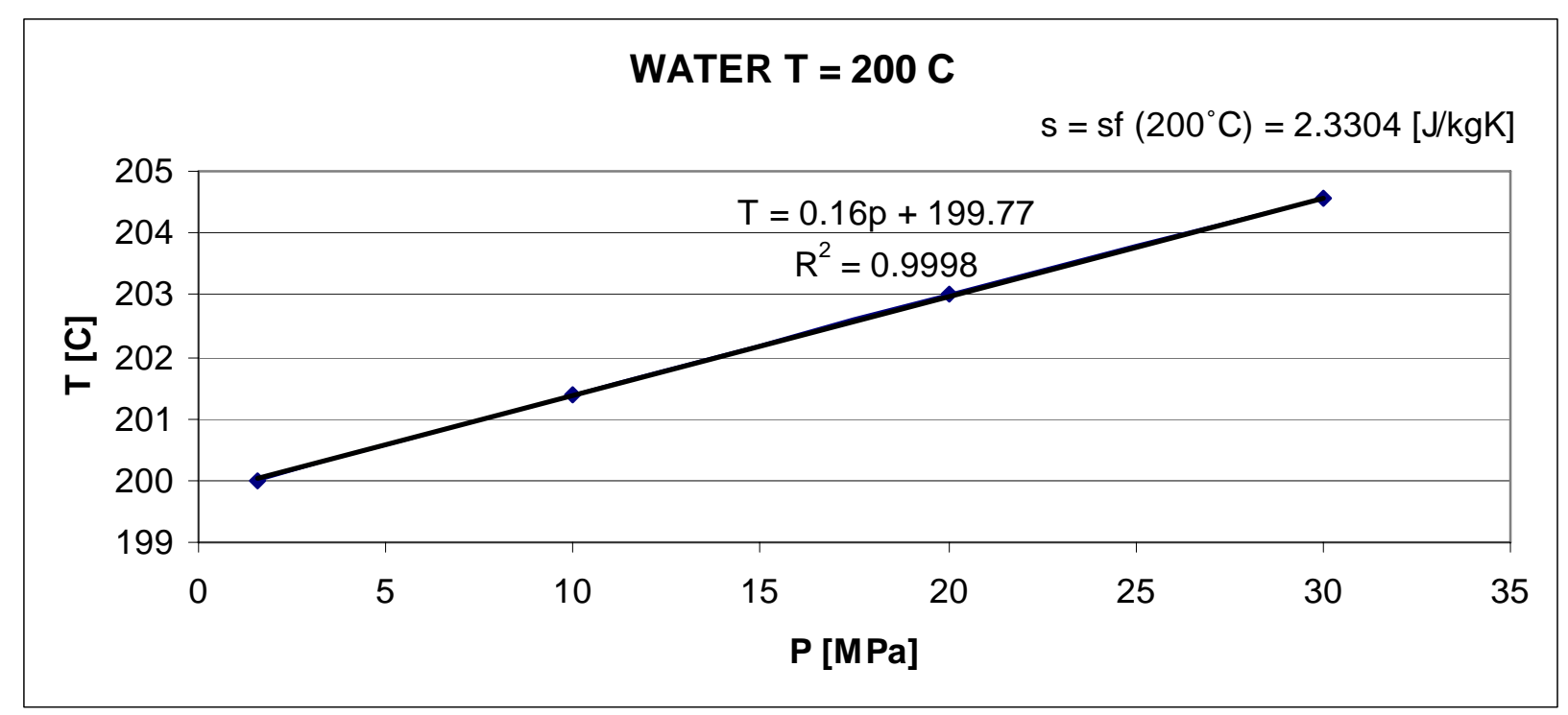

Figure 2. Temperature trend versus pressure along an isentrop

The proposed approximation is based on the specific internal energy of saturated liquid evaluated at a temperature, $\mathrm{T}^{\prime}$, determined from the following procedure. We find the temperature at a given pressure using equation (44). Then we find the temperature rise along the isentrop

$$
\Delta \mathrm{T}=\mathrm{T}\left(\mathrm{s}_{\mathrm{f}}, \mathrm{p}\right)-\mathrm{T}_{\mathrm{sat}}
$$

Now $T^{\prime}$ is calculated by,

$$
\mathrm{T}^{\prime}=\mathrm{T}_{\text {sat }}-\Delta \mathrm{T}
$$

Then,

$$
\mathrm{u}(\mathrm{T}, \mathrm{p}) \approx \mathrm{u}_{\mathrm{f}}\left(\mathrm{T}^{\prime}\right)
$$

Table 4 shows the approximation of internal energy for Water at a temperature of $200{ }^{\circ} \mathrm{C}$. For example the specific internal energy at $200{ }^{\circ} \mathrm{C}$ and $10 \mathrm{MPa}$ is $844.31 \mathrm{~kJ} / \mathrm{kg}$, with an existing approximation, $\mathrm{u}(\mathrm{T}, \mathrm{p}) \approx \mathrm{u}_{\mathrm{f}}(\mathrm{T}), 850.47 \mathrm{~kJ} / \mathrm{kg}$. Using the proposed approximation, $\mathrm{u}(\mathrm{s}, \mathrm{p})=\mathrm{u}_{\mathrm{f}}(\mathrm{s})$ $=\mathrm{u}_{\mathrm{f}}(\mathrm{T}-\Delta \mathrm{T})$, specific internal energy is $844.27 \mathrm{~kJ} / \mathrm{kg}$. Results show that estimating internal energy with the new method gives much more accurate as compared with result the existing approximation of internal energy, $u(p, T)=u_{f}(T)$. Equation 2.33 can be expressed generally

$$
\mathrm{T}^{\prime}=\mathrm{ap}+\mathrm{b}
$$

Where $\mathrm{p}$ is pressure, $\mathrm{a}$ and $\mathrm{b}$ are constants. The constants in equation (48) are given in Table 5 
Table 4. Approximation of specific internal energy at $\mathrm{s}_{\mathrm{f}}=2.3305 \mathrm{~J} / \mathrm{kgK}$

\begin{tabular}{|c|c|c|c|}
\hline \multicolumn{4}{|c|}{ WATER } \\
\hline $\mathrm{u}\left(200{ }^{\circ} \mathrm{C}, 10 \mathrm{Mpa}\right)$ & $\mathrm{u}_{\mathrm{f}}\left(200{ }^{\circ} \mathrm{C}\right)$ & $\mathrm{T}\left(\mathrm{s}_{\mathrm{f}}, 10 \mathrm{Mpa}\right)$ & $\mathrm{u}_{\mathrm{f}}\left(198.61{ }^{\circ} \mathrm{C}\right)$ \\
\hline$[\mathrm{kJ} / \mathrm{kg}]$ & {$[\mathrm{kJ} / \mathrm{kg}]$} & ${ }^{\circ} \mathrm{C}$ & {$[\mathrm{kJ} / \mathrm{kg}]$} \\
\hline 844.31 & 850.47 & 201.39 & 844.27 \\
\hline $\mathrm{u}\left(200{ }^{\circ} \mathrm{C}, 20 \mathrm{Mpa}\right)$ & $\mathrm{u}_{\mathrm{f}}\left(200{ }^{\circ} \mathrm{C}\right)$ & $\mathrm{T}\left(\mathrm{s}_{\mathrm{f}}, 20 \mathrm{Mpa}\right)$ & $\mathrm{u}_{\mathrm{f}}\left(197{ }^{\circ} \mathrm{C}\right)$ \\
\hline$[\mathrm{kJ} / \mathrm{kg}]$ & {$[\mathrm{kJ} / \mathrm{kg}]$} & ${ }^{\circ} \mathrm{C}$ & {$[\mathrm{kJ} / \mathrm{kg}]$} \\
\hline 837.49 & 850.47 & 203 & 837.09 \\
\hline & & & \\
\hline $\mathrm{u}\left(200{ }^{\circ} \mathrm{C}, 30 \mathrm{Mpa}\right)$ & $\mathrm{u}_{\mathrm{f}}\left(200{ }^{\circ} \mathrm{C}\right)$ & $\mathrm{T}\left(\mathrm{s}_{\mathrm{f}}, 30 \mathrm{Mpa}\right)$ & $\mathrm{u}_{\mathrm{f}}\left(195.45{ }^{\circ} \mathrm{C}\right)$ \\
\hline$[\mathrm{kJ} / \mathrm{kg}]$ & {$[\mathrm{kJ} / \mathrm{kg}]$} & ${ }^{\circ} \mathrm{C}$ & {$[\mathrm{kJ} / \mathrm{kg}]$} \\
\hline 831.1 & 850.47 & 204.55 & 830.19 \\
\hline
\end{tabular}

Table 5. Variations constants a and $\mathrm{b}$ with pressure

\begin{tabular}{|c|c|c|c|c|c|c|c|c|}
\hline T $[\mathbf{C}]$ & $\mathrm{a}$ & $\mathrm{b}$ & $\mathbf{T}[\mathbf{C}]$ & $\mathrm{a}$ & $\mathrm{b}$ & $\mathbf{T}[\mathbf{C}]$ & $\mathrm{a}$ & $\mathrm{b}$ \\
\hline $\mathbf{5}$ & 0.0036 & 4.99 & $\mathbf{1 0 5}$ & 0.0708 & 105.00 & $\mathbf{2 0 5}$ & 0.1553 & 204.74 \\
\hline $\mathbf{1 0}$ & 0.0079 & 9.99 & $\mathbf{1 1 0}$ & 0.0744 & 110.00 & $\mathbf{2 1 0}$ & 0.1602 & 209.69 \\
\hline $\mathbf{1 5}$ & 0.0121 & 14.99 & $\mathbf{1 1 5}$ & 0.0782 & 115.00 & $\mathbf{2 1 5}$ & 0.1654 & 214.65 \\
\hline $\mathbf{2 0}$ & 0.0158 & 20.00 & $\mathbf{1 2 0}$ & 0.0814 & 120.00 & $\mathbf{2 2 0}$ & 0.1703 & 219.60 \\
\hline $\mathbf{2 5}$ & 0.0196 & 25.00 & $\mathbf{1 2 5}$ & 0.0855 & 125.00 & $\mathbf{2 2 5}$ & 0.1764 & 224.53 \\
\hline $\mathbf{3 0}$ & 0.0231 & 30.00 & $\mathbf{1 3 0}$ & 0.0887 & 129.98 & $\mathbf{2 3 0}$ & 0.1818 & 229.46 \\
\hline $\mathbf{3 5}$ & 0.0266 & 35.00 & $\mathbf{1 3 5}$ & 0.0926 & 134.98 & $\mathbf{2 3 5}$ & 0.1905 & 234.40 \\
\hline $\mathbf{4 0}$ & 0.0296 & 40.00 & $\mathbf{1 4 0}$ & 0.0963 & 139.97 & $\mathbf{2 4 0}$ & 0.1930 & 239.29 \\
\hline $\mathbf{4 5}$ & 0.0330 & 45.00 & $\mathbf{1 4 5}$ & 0.1003 & 144.97 & $\mathbf{2 4 5}$ & 0.1980 & 244.18 \\
\hline $\mathbf{5 0}$ & 0.0360 & 50.00 & $\mathbf{1 5 0}$ & 0.1047 & 149.96 & $\mathbf{2 5 0}$ & 0.2037 & 249.07 \\
\hline $\mathbf{5 5}$ & 0.0394 & 55.00 & $\mathbf{1 5 5}$ & 0.1086 & 154.95 & $\mathbf{2 5 5}$ & 0.2090 & 253.94 \\
\hline $\mathbf{6 0}$ & 0.0422 & 60.00 & $\mathbf{1 6 0}$ & 0.1132 & 159.94 & $\mathbf{2 6 0}$ & 0.2143 & 258.78 \\
\hline $\mathbf{6 5}$ & 0.0452 & 65.00 & $\mathbf{1 6 5}$ & 0.1172 & 164.93 & $\mathbf{2 6 5}$ & 0.2205 & 263.61 \\
\hline $\mathbf{7 0}$ & 0.0484 & 70.00 & $\mathbf{1 7 0}$ & 0.1217 & 169.92 & $\mathbf{2 7 0}$ & 0.2255 & 268.41 \\
\hline $\mathbf{7 5}$ & 0.0518 & 75.00 & $\mathbf{1 7 5}$ & 0.1259 & 174.90 & $\mathbf{2 7 5}$ & 0.2307 & 273.19 \\
\hline $\mathbf{8 0}$ & 0.0548 & 80.00 & $\mathbf{1 8 0}$ & 0.1305 & 179.88 & $\mathbf{2 8 0}$ & 0.2358 & 277.93 \\
\hline $\mathbf{8 5}$ & 0.0580 & 85.00 & $\mathbf{1 8 5}$ & 0.1352 & 184.86 & $\mathbf{2 8 5}$ & 0.2405 & 282.65 \\
\hline $\mathbf{9 0}$ & 0.0612 & 90.00 & $\mathbf{1 9 0}$ & 0.1403 & 189.84 & $\mathbf{2 9 0}$ & 0.2448 & 287.31 \\
\hline $\mathbf{9 5}$ & 0.0644 & 95.00 & $\mathbf{1 9 5}$ & 0.1454 & 194.81 & $\mathbf{2 9 5}$ & 0.2487 & 291.93 \\
\hline $\mathbf{1 0 0}$ & 0.0676 & 100.00 & $\mathbf{2 0 0}$ & 0.1500 & 199.77 & $\mathbf{3 0 0}$ & 0.2524 & 296.49 \\
\hline & & & & & & & &
\end{tabular}


Table 6 shows the properties and percentage changes for water at $\mathrm{s}=\mathrm{s}_{\mathrm{f}}\left(300^{\circ} \mathrm{C}\right)$ for different values of pressure starting from saturation pressure to $30 \mathrm{MPa}$. The results show that in this range of pressures the maximum changes are $-3.19 \%$ for the specific volume, and $0.07 \%$ for the internal energy.

Table 6. Variation of specific volume and internal energy at along an isentrop for water

\begin{tabular}{|c|c|c|c|c|c|c|c|}
\hline & $\mathrm{P}$ & $\mathrm{T}$ & $\mathrm{s}$ & $\mathrm{v}(\mathrm{T}, \mathrm{s})$ & $\begin{array}{c}\% \text { change } \\
\text { in v }\end{array}$ & $\mathrm{u}(\mathrm{T}, \mathrm{s})$ & $\begin{array}{c}\% \text { change } \\
\text { in u }\end{array}$ \\
\hline & {$[\mathrm{Mpa}]$} & {$[\mathrm{C}]$} & {$[\mathrm{J} / \mathrm{kgK}]$} & {$[\mathrm{m} 3 / \mathrm{kg}]$} & & {$[\mathrm{kJ} / \mathrm{kg}]$} & \\
\hline sat & 8.5879 & 300.00 & 3.2552 & 0.0014042 & 0.00 & 1332.90 & 0.00 \\
\hline comp & 10 & 300.65 & 3.2552 & 0.0014009 & -0.24 & 1333.02 & 0.01 \\
\hline comp & 20 & 304.95 & 3.2552 & 0.0013790 & -1.83 & 1333.31 & 0.03 \\
\hline comp & 30 & 308.89 & 3.2552 & 0.0013608 & -3.19 & 1333.82 & 0.07 \\
\hline
\end{tabular}

Table 7 shows the properties and error calculations for water at $300{ }^{\circ} \mathrm{C}$ for different values of pressure starting from saturation pressure to $100 \mathrm{MPa}$. The results show that in these range of pressures the maximum percentage changes are $-15.59 \%$ for specific volume, $-10.38 \%$ for internal energy, $10.85 \%$ for enthalpy and $-7.72 \%$ for entropy. It is seen in Table 3.6 that the absolute errors associated with the approximation of internal energy are lower then those for enthalpy for all the pressures.

Table 7. Variation of specific volume, internal energy, enthalpy and entropy of water with pressure along the isotherm $\mathrm{T}=300^{\circ} \mathrm{C}$

\begin{tabular}{|c|c|c|c|c|c|c|c|c|c|}
\hline $\mathbf{p}^{*}$ & $\mathbf{v}(\mathbf{T}, \mathbf{p})^{*}$ & $\begin{array}{c}\% \\
\text { Error } \\
\quad \mathbf{v}\end{array}$ & $\mathbf{u}(\mathbf{T}, \mathbf{p})^{*}$ & $\begin{array}{c}\% \\
\text { Error } \\
\mathbf{u}\end{array}$ & $\mathbf{h}_{\text {app }}$ & $\mathbf{h}(\mathbf{T}, \mathbf{p})^{*}$ & $\begin{array}{c}\% \\
\text { Error } \\
\mathbf{h}_{\text {app }}\end{array}$ & $\mathbf{s}(\mathrm{T}, \mathrm{p})^{*}$ & $\begin{array}{c}\% \\
\text { Error } \\
\text { s }\end{array}$ \\
\hline [Mpa] & {$\left[\mathrm{m}^{3} / \mathrm{kg}\right]$} & & [kJ/kg] & & [kJ/kg] & {$[\mathrm{kJ} / \mathrm{kg}]$} & & [kJ/kgK] & \\
\hline 8.5879 & 0.0014042 & 0.00 & 1332.9 & 0.00 & 1345.0 & 1345.0 & 0.00 & 3.2552 & 0.00 \\
\hline 10 & 0.0013980 & -0.44 & 1329.4 & -0.26 & 1347.0 & 1343.3 & 0.27 & 3.2488 & -0.20 \\
\hline 15 & 0.0013783 & -1.88 & 1317.6 & -1.16 & 1354.0 & 1338.3 & 1.17 & 3.2279 & -0.85 \\
\hline 20 & 0.0013611 & -3.17 & 1307.1 & -1.97 & 1361.0 & 1334.4 & 2.00 & 3.2091 & -1.44 \\
\hline 30 & 0.0013322 & -5.40 & 1288.9 & -3.41 & 1375.1 & 1328.9 & 3.47 & 3.1760 & -2.49 \\
\hline
\end{tabular}

*First row represents the saturation property

\section{Range of Application for Approximation Equations}

It is presented that the errors resulting from using equations (1), (2), (3) and (10) in predicting the thermodynamic properties of few fluids in the compressed liquid region. It was shown that the current approximation equations result in unacceptable errors at high pressures. In this section we will shoe the range of pressures when the approximation equation results in errors less than 2\%. Figure 3 shows the range of pressure when the errors in approximation of specific 
volume, internal energy, entropy and enthalpy resulting from the applications of equations (1), (2), (1.3) and (10) falls below $2 \%$. The line identified by " $2 \%$ error limit" represents the limit of pressure when the changes are less the $2 \%$. Therefore the region bounded by the saturation curve and the $2 \%$ error limit defines the range of applications of equations (1), (2), (3) and (10)

Figure 3 presents the range of application of approximation equations for water in the compressed liquid region. The figure shows that error will be less then $2 \%$ for low temperatures (less than $150{ }^{\circ} \mathrm{C}$ ) at pressures lower then $30 \mathrm{MPa}$. For temperatures in the range of $150{ }^{\circ} \mathrm{C}$ and $300{ }^{\circ} \mathrm{C}$, the limit of application is for pressures less than $20 \mathrm{Mpa}$.

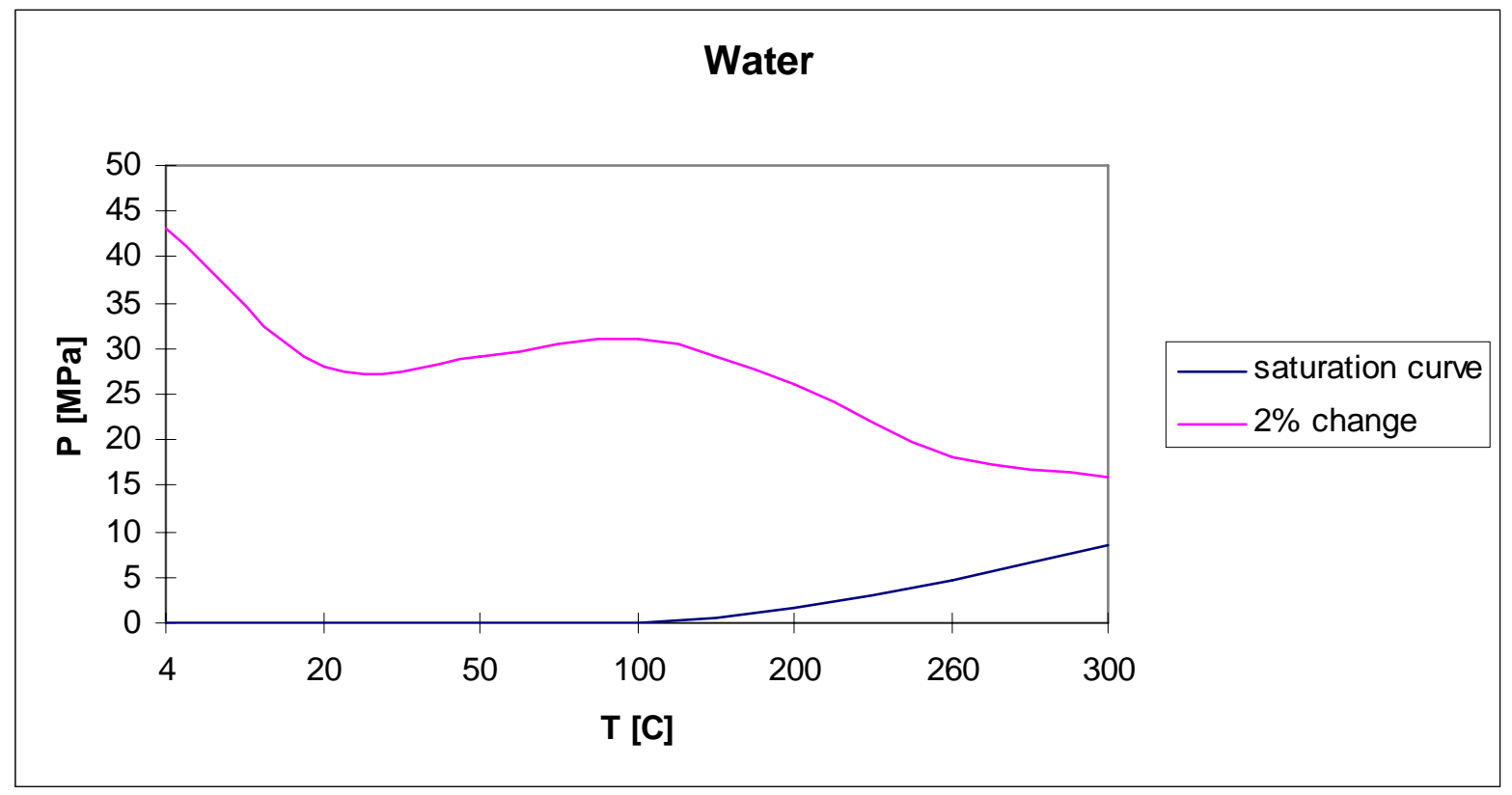

Figure 3. Application range of approximation equations for compressed liquid water (errors $\leq 2 \%$ )

\section{Summary and Conclusions}

Standard practice in approximating of main thermodynamic properties in the compressed liquid region is investigated and error resulting from the use of general approximation equations

$$
\begin{aligned}
& \mathrm{v}(\mathrm{T}, \mathrm{p}) \approx \mathrm{v}_{\mathrm{f}}(\mathrm{T}) \\
& \mathrm{u}(\mathrm{T}, \mathrm{p}) \approx \mathrm{u}_{\mathrm{f}}(\mathrm{T}) \\
& \mathrm{h}(\mathrm{p}, \mathrm{T})=\mathrm{h}_{\mathrm{f}}(\mathrm{T})+\mathrm{v}_{\mathrm{f}}(\mathrm{T})\left[\left(\mathrm{p}-\mathrm{p}_{\mathrm{sat}}(\mathrm{T})\right]\right.
\end{aligned}
$$

are evaluated. It is shown that equations

$$
\begin{aligned}
& \mathrm{u}(\mathrm{s}, \mathrm{p}) \approx \mathrm{u}_{\mathrm{f}}(\mathrm{s}) \\
& \mathrm{v}(\mathrm{s}, \mathrm{p}) \approx \mathrm{v}_{\mathrm{f}} \\
& \mathrm{h}(\mathrm{s}, \mathrm{p})=\mathrm{h}_{\mathrm{f}}(\mathrm{s})+\mathrm{v}_{\mathrm{f}}(\mathrm{s})\left[\mathrm{p}-\mathrm{p}_{\mathrm{sat}}(\mathrm{s})\right]
\end{aligned}
$$


are more accurate approximation equations in the compressed liquid region. Analysis showed that approximating the specific volume, internal energy and enthalpy along a constant entropy line will result reduce errors as compared when those properties are approximated along an isotherm. Therefore it is suggested in this work that properties should be calculated isentropically rather than isothermally in the compressed liquid region.

Also a new approximation method was developed in this work by approximating compressed liquid properties based on the saturation properties along an isentropic line.

\section{References}

1. Cengel Y. A., and Boles, M. A., 2002 Thermodynamics Engineering Approach, 4 ${ }^{\text {th }}$ ed., McGraw-Hill, New York.

2. Moran, M. J. and Shapiro, H. N., 2000, Fundamentals of Engineering Thermodynamics, $5^{\text {th }}$ ed., Wiley, New York.

3. Kostic, M. M., 2006, -Analysis of enthalpy approximation for compressed liquid water," Journal of Heat Transfer, Vol 28, pp. 421-426.

4. Kostoc, M, 2004 -Analysis of Enthalpy Approximation for Compressed Liquid Water," Preceedings of IMECE2004, Anaheim.

5. Keenan, J. H., Keyes, F. G., Hill, P. J. and Moore, J. G., 1969, 1967 Steam Tables, John Wiley \& Sons, New York.

6. Karimi, A. and Lienhard J.H., 1983, A Fundamental Equation Representing Water in the Stable, Metastable, and

Unstable States, EPRI, Houston.

7. Wagner, W. and Pruss, A., 2002, -The IAPWS formulation 1995 for the thermodynamic properties of ordinary water substance for general and scientific use”, J. Phys. Chem. Ref. Data, Vol 31, No. 2., pp. 387-535.

8. Lemmon, E.W. McLinden M.O., 2005 "Thermophysical Properties of Fluid Systems", NIST Chemistry WebBook, NIST Standard Reference Database Number 69, Eds. P.J. Linstrom and W.G. Mallard, Gaithersburg MD, URL http://webbook.nist.gov.

9. Setzmann, U., and Wagner, W., 1991, -A New Equation of State and Tables of Thermodynamic Properties for Methane Covering the Range from the Melting Line to $625 \mathrm{~K}$ at Pressures up to 1000 Mpa", J. Phys. Chem. Ref.

Data, Vol 20, No. 6, pp. 1061-1151.

10. Miyamoto, H., and Watanabe, K., 2000, -A thermodynamic property model for fluid-phase propane”, Int. J. Thermophys., Vol. 21, No. 5., pp. 1045-1072.

11. Tillner-Roth, R.,Harms-Watzenberg, F., and Baehr, H.D., 1993, -Eine neue Fundamentalgleichung für Ammoniak",

DKV-Tagungsbericht, Vol. 20, pp. 167-181.

\section{ISA TAN}

Mr Tan is currently pusuing masters degree in Mechanical Engineering The University of Texas at San Antonio. His research interest is in Thermal-Fluid area.

\section{AMIR KARIMI}

Amir Karimi is a Professor of Mechanical Engineering and an Associate Dean of Undergraduate Studies at The University of Texas at San Antonio (UTSA). He received his Ph.D. degree in Mechanical Engineering from the University of Kentucky in 1982. His teaching and research interests are in thermal sciences. He has served as the Chair of Mechanical Engineering (1987 to 1992 and September 1998 to January of 2003), College of Engineering Associate Dean of Academic Affairs (Jan. 2003-April 2006), and the Associate Dean of Undergraduate Studies 
(April 2006-present). Dr. Karimi is a Fellow of ASME, senior member of AIAA, and holds membership in ASEE, ASHRAE, and Sigma Xi. He is the ASEE Campus Representative at UTSA, ASEE-GSW Section Campus Representative, and served as the Chair of ASEE Zone III (2005-07). He chaired the ASEE-GSW section during the 1996-97 academic year. 